\title{
Certified reference materials for breath alcohol control - the ALCOREF project
}

\author{
Béatrice Lalere ${ }^{1, *}$, Fanny Gantois ${ }^{1}$, Rosemarie Philipp ${ }^{2}$ and Sophie Vaslin-Reimann ${ }^{1}$ \\ ${ }^{1}$ Laboratoire National de Métrologie et d'Essais (LNE), Chemistry and biology division, 75724 Paris \\ cedex 15 , France \\ ${ }^{2}$ Bundesanstalt für Materialforschung und -prüfung (BAM), Division 1.8 Environmental Analysis, \\ 12489 Berlin, Germany
}

\begin{abstract}
The Joint Research Project Alcoref "Certified forensic alcohol reference materials" is a multi-partner trans-national project within the targeted call "Research Potential" of the European Metrology Programme for Innovation and Research (EMPIR) launched in 2016. The European Commission has estimated that about one quarter of road traffic deaths are due to alcohol. The European status report on road safety of the World Health Organization Regional Office for Europe therefore stated that, among other measures, better legislation and enforcement of alcohol control is needed in several countries. In particular, the report demands that unrestricted access to alcohol breath testing, using breath analysers of equivalent and agreed standard, should be implemented throughout Europe. These high standards for tests, verification and calibration of breath alcohol analysers should meet some requirements of the recommendation R 126 defined by the International Organization of Legal Metrology (OIML) and European standards (EN 16280 and EN 15964). The specific objective of this project is to establish regional research and metrological capacity for the development of certified forensic alcohol reference materials for the law enforcement of drink-driving regulations.
\end{abstract}

\section{Overview}

The European status report on road safety of the World Health Organization (WHO) Regional Office for Europe [1] demands better enforcement of drink-driving legislation in several European countries. The research in this project will address this need by building up long term capacities for the production and certification of forensic alcohol reference materials suitable for tests, verification and calibration of breath alcohol analysers according the requirements of both European standards (EN 16280 [2] and EN 15964 [3]) and OIML R 126 [4]. Certification includes characterisation of the materials, assessment of homogeneity, stability, and measurement uncertainty. Ethanol concentrations will meet regional legal limits for alcohol control. An interlaboratory comparison will be conducted within the EURAMET Technical Committee Metrology in Chemistry (TC-MC) and the

${ }^{*}$ Corresponding author: beatrice.lalere@lne.fr 
Organic Analysis Working Group (OAWG) of the CCQM to test the materials and capabilities developed.

\section{Need}

The European Commission has estimated that about one quarter of road traffic deaths are due to alcohol [5]. However, there are big differences regarding the number of victims with the Nordic countries having far lower death rates than the Baltic countries or Southern Europe. The EU has set itself a target of halving the number of people killed by traffic accident by 2020 [3,6]. The European status report on road safety [1] therefore stated that, among other measures, better legislation and enforcement of alcohol control is needed in several countries. In particular, the report demands that unrestricted access to alcohol breath testing, using breath analysers of equivalent and agreed standard, should be implemented throughout Europe.

According to European standards and OIML R 126 [4], a test gas similar to human breath is required with a defined concentration of alcohol. One possibility to generate such gases is to could bubble air through an aqueous ethanol solution (wet bath simulator), and another one is to generate such gas by gas and liquid mass flow controllers system managed by a gas analyzer.

Large volumes of ethanol in water solutions are necessary and the ethanol content should ideally be certified, i.e. traceable to the SI, accompanied by uncertainty, stability and homogeneity data. At the beginning of the project, there were only two European NMIs that produce such materials. Due to the different national approaches and the large volumes needed, it appeared important that more European countries would be able to produce their own traceable certified ethanol in water reference materials in large quantities tailored for their regional needs. However, the metrological quality (homogeneity, stability, uncertainty, traceability) of the materials developed at different NMIs should be equivalent in so far as they should meet some requirements of both European standards and OIML R 126.

\section{Objectives}

The overall objective of the project is to establish regional research and metrological capacity for the development of certified forensic alcohol reference materials for the law enforcement of drink-driving regulations.

The specific objectives of the project are:

1. To develop traceable measurement and production capabilities for certified ethanol in water reference materials at NMIs/DIs. Values and measurement ranges to be covered should address legal limits of regional drink-driving legislation.

2. To enable NMIs/DIs to produce forensic alcohol reference materials following an appropriate quality system according to ISO Guides 30 to 35 [7]. This includes assessment of homogeneity, short and long term stability, and uncertainty, as well as appropriate documentation, drafting of certificates and certification reports. Certified values should be traceable to the SI. Measurement capabilities and 
reference materials developed should be at a metrological level high enough for entries into the BIPM CMC database [8].

3. To conduct a EURAMET TC-MC and OAWG intercomparison to test the reference materials and measurement capabilities developed within the project.

4. For each emerging NMI/DI (BRML (Biroul Roman de Metrologie Legala, Romania), CEM (Centro Español de Metrología, Spain), GUM (Central Office of Measures, Poland), IMBiH (Institut za mjeriteljstvo Bosne i Hercegovine), MoE (Ministry of Economy, Serbia), TUBITAK (Turkiye Bilimsel ve Teknolojik Arastirma Kurumu, Turkey), FTMC (Valstybinis mokslinių tyrimų institutas Fizinių ir technologijos mokslų centras, Lithuania), IAPR (Independent Authority for Public Revenue, Greece)), to develop a country specific strategy for the long-term development of their measurement and production capabilities by specifying the collaborations with regional stakeholders such as calibration authorities, reference materials producers, standardisation and accreditation bodies, and manufacturers of breath analysers. NMIs/DIs should develop plans to offer services and products from the newly established capacities. Individual strategies should be discussed within the consortium and with other EURAMET or CCQM NMIs/DIs, to ensure that a coordinated and optimised approach is developed.

\section{Overview of the scientific and technical objectives}

The overall objective of the project is to establish regional research and metrological capacity for the development of certified forensic alcohol reference materials suitable for the law enforcement of drink-driving regulations, starting from a review of existing capabilities and needs, validation of existing systems and, if required, improvement or development of new systems (fig. 1). 


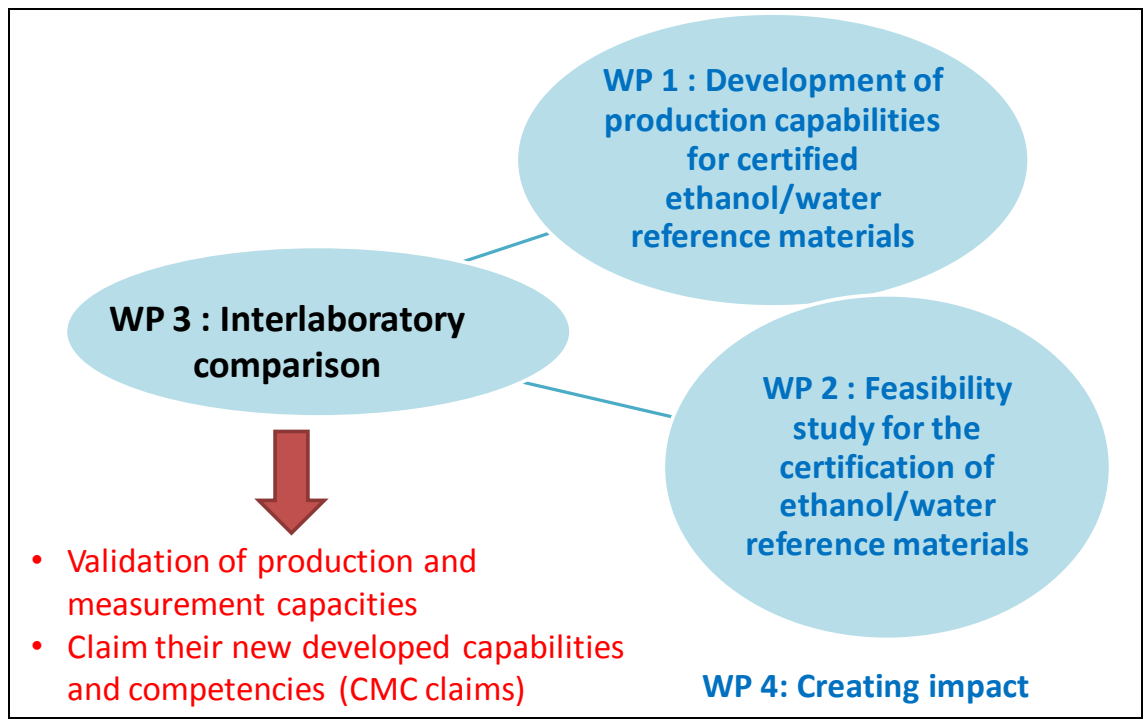

Fig. 1. Schematic representation of the project

The specific objectives of the project are:

1. To develop traceable production capabilities for ethanol in water reference materials at NMIs and DIs seeking to establish research capacity in this field. The range of materials should be suitable for tests, verification and calibration of breath alcohol analysers Values and measurement ranges to be covered should address legal limits of regional/national drink-driving legislation. (WP1)

2. To develop and implement agreed, common techniques to certify forensic alcohol reference materials following an appropriate quality system according to ISO Guides 30 to 35 . The certified values should be traceable to the SI and include appropriate assessment of homogeneity, short and long term stability and uncertainties. The measurement capabilities and reference materials developed should be at a metrological level suitable for participation in CCQM intercomparisons and $\mathrm{CMC}$ entries into the BIPM key comparison database. This may involve improvements to existing techniques for those NMIs/DIs that have some basic capability in the field. (WP2)

3. To undertake a EURAMET TC-MC intercomparisons to evaluate the quality and metrological integrity of the reference materials produced and the associated measurement and certification techniques. (WP3)

4. For each emerging NMI and DI, to develop an individual strategy for the longterm operation and development of their measurement and production capacities, including regulatory support, research collaborations, quality schemes and accreditation. They should also develop a strategy for offering calibration services from the established facilities to their own country and neighbouring countries. The individual strategies should be discussed within the consortium and with other 
EURAMET NMIs/DIs, to ensure that a coordinated and optimised approach to the development of traceability in this field is developed for Europe as a whole. (WP4)

\section{Impact}

\subsection{Impact on industrial and other user communities}

The main stakeholder groups which will directly benefit from the outcome of the project are the end-users of the certified materials to be developed - manufacturers and service providers of breath analysers, the national calibration/verification authorities and calibration laboratories, and the national police. Currently, many end-users buy the CRMs from two suppliers (LNE and BAM) and this has led to logistical issues. A better solution is to have the capabilities in each country at the national NMI/DI. This project will enable more and higher accuracy reference materials to be available to the community, allowing higher accuracy calibration and verification of breath alcohol analysers to be made with greater confidence.

Several partners already have close links to such stakeholders in their countries; others will establish these links in the course of the project. The on-going interaction with stakeholders will also be achieved through the stakeholder committee. The partners will systematically engage with the target user communities via ad-hoc meetings, the website, the final workshop organised at the end of the project, and international technical working group meetings as well as presenting the project's results at metrology conferences and in practitioner journals. Furthermore, new CMC claims and the registered new reference materials in international databases such as COMAR [7] will raise the awareness of the project results and consequently will promote uptake by end-users.

\subsection{Impact on metrology and scientific communities}

Several NMIs/DIs will directly benefit from the project by their newly established production and measurement capabilities. The certified materials themselves will also be achievements for the partners, since they will enable them to provide new services. The materials will allow the measurements traceability. Therefore the project will help to maintain comparable and equivalent national measurement standards in the field Europe-wide.

The intercomparisons organised within the project will be opened to other European and CCQM OAWG NMIs/DIs. This will allow them to compare their available or new measurement capabilities and reference materials with the ones developed in the project. New CMC claims or support for existing claims provided by the intercomparison results will increase national and international reputation of the participating NMIs.

\subsection{Impact on relevant standards}

The project will actively support knowledge exchange with key international and European metrology and legal committees such as CCQM OAWG, EURAMET TC-MC 
Subcommittee for Organic Analysis and CEN/TC 367 Project Committee - Breath alcohol testers. The link is particularly important since the OIML recommendation $\mathrm{R} 126$ is currently under review but also for European standards which are regularly under review . The project will actively exchange information with both OIML TC17/SC7 Breath testers and European standards committees and provide input to the revised recommendation if appropriate. The committees will be informed about project's progress and will be asked for feedback.

Furthermore, the partners who are members of relevant national technical committees or organisations will inform them about the results of this project and will seek feedback, a list of committees and the partners involved is provided in WP Impact.

\section{References}

1. European status report on road safety: towards safer roads and healthier transport choices. Copenhagen, WHO Regional Office for Europe, Copenhagen, (2009), https://www.euro.who.int/_data/assets/pdf_file/0015/43314/E92789.pdf, accessed 10.07.2016.

2. EN 16280 (2012) -Breath alcohol test devices for general public - Requirements and test methods

3.EN 15964 (2011) - Breath alcohol test devices other than single use devices Requirements and test methods

4. OIML $\mathrm{R} \quad 126: 2012$ Evidential breath analyzers, https://www.oiml.org/en/files/pdf_r/r126-e12.pdf, accessed 10.07.2016.

5. Drinking and Driving in Europe, a Eurocare report to the European Union, Brussels, (2003).

6. P. Anderson, Reducing drinking and driving in Europe. Report, German Centre for Addiction Issues (DHS) Hamm, Germany, (2008), https://www.dhs.de/fileadmin/user_upload/pdf/Pathways_for_Health-

Project/reducing_drinking_and_driving_report.pdf, accessed 20.07.2016.

7. ISO Guide 30:2015, Reference materials -- Selected terms and definitions; ISO Guide 31:2015, Reference materials -- Contents of certificates, labels and accompanying documentation; ISO Guide 33:2015, Reference materials -- Good practice in using reference materials; ISO Standard 17034:2016, General requirements for the competence of reference material producers; ISO Guide 35:2017, Reference materials -- Guidance for characterization and assessment of homogeneity and stability, ISO, Geneva, Switzerland. 
8. CMCs-the BIPM key comparison database, https://kcdb.bipm.org/appendixc/, accessed 19.07.2016. 